\title{
Clinical Pharmacy: Looking 20 Years Back... Looking 20 Years Forward
}

\author{
David M. Angaran, M.Sc., Joaquim Bonal, Ph.D., Grethe Eide, D.Sc., \\ Mary Anne Koda-Kimble, Pharm.D., Kathleen D. Lake, Pharm.D., \\ and Hubert G. M. Leufkens, Pharm.D., Ph.D.
}

(Pharmacotherapy 2000;20(10 Pt 2):235S-242S)

To me the concept of clinical pharmacy is the freshest, most invigorating, most challenging and exciting breeze that has blown across the horizons of pharmacy in any land for generations. I hope that its message will ring loud and clear to pharmacists all over the world, and that it will be the source of a new inspiration to pharmacists everywhere.

\section{Donald E. Francke ${ }^{1}$}

Angaran: We have two main goals in this panel discussion. First, to describe the current status of the health care delivery environment, the medication use system, and the pharmacy profession. And second, to discuss the specific challenges and opportunities for pharmacy over the next 5-10 years. Our hope is that you identify at least one specific action that you can apply that will catalyze change in your professional practice, regardless of your country of origin.

Our discussion will be in three sections. The first part will concentrate on the broad topics of health care and the health care environment, admittedly from only the

The International Congress on Clinical Pharmacy began with a panel discussion of pharmacy thought leaders from the United States and Europe. Moderator: David Angaran, M.Sc., Chief Clinical Officer, cranespharmacy.com. Panelists: Joaquim Bonal, Ph.D., President, Pharmaceutical Care Foundation, Barcelona, Spain; Grethe Eide, D.Sc., Director, Hjorten Pharmacy, Fredrikstad, Norway; Kathleen Lake, Pharm.D., Director, Clinical Research and Transplant Therapeutics, Departments of Medicine and Surgery, University of Michigan; Mary Anne Koda-Kimble, Pharm.D., Dean, School of Pharmacy, University of California-San Francisco; and Hubert Leufkens, Pharm.D., Ph.D., Professor of Pharmacoepidemiology, Utrecht University, The N etherlands.
European and United States' perspectives. The second part will deal with pharmacy specifically, and how pharmacy should respond to these environmental changes. And finally, we will close with specific recommendations from each panelist.

Bert, you have written about future scenarios regarding medication use in health care. Probably every country in the world is faced with a demand for health care that exceeds the resources available to support that health care. In the U.S., spending on prescription pharmaceuticals constitutes $7-11 \%$ of total health care expenditures-and that percentage is rising. Further, the cost of pharmaceuticals is rising at a faster rate than any other segment of health care. Recognizing that differences exist among countries, can you provide a perspective on the current status of health care systems in Europe and comment on important trends that you envision over the next 5 years?

Leufkens: Just as is true in the U.S., the health care environment is changing very rapidly in most of Europe. Some major trends that are affecting patients and health care providers include technologic and information science advances, a changing European economy, a shift in disease burden, and of course, European harmonization. To give an example of how changing disease burden is affecting the health care system, we are doing a project on congestive heart failure and have observed a tremendous increase in its prevalence-partly because we have improved our treatment of acute myocardial infarction. Thus, as we reduced mortality from an acute medical 
problem, we increased the prevalence of a chronic disease that requires long-term management. This kind of shift will have a great impact on health care resource utilization.

Of course, those who pay for health carelargely the government in most European countries- are placing increased emphasis on controlling costs. Certainly one of the major trends affecting the health care system in Europe at this time is harmonization, including the registration of pharmaceuticals. Even though we're working to harmonize the registration of pharmaceuticals, the individual member States are still responsible for their own health policy, including payment policies for medicines. This can cause tension among countries that adopt conflicting policies regarding payment for a given drug. We are working to harmonize health policy across member countries of the European Union.

Angaran: Mary Anne, a similar question to you. What features do you think generally characterize the U.S. health care system today, and what are the emerging trends likely to affect pharmacists and their patients over the next 5 years?

Koda-Kimble: I think the phrase "health care system" is an oxymoron as it describes the U.S. The last decade produced tremendous change, which actually resulted in a sense of turmoil among both patients and health care providers. In the minds of some people, this has reached crisis proportions. Driven by economics and the high cost of health care, there has been a corporatization of health care in the U.S. This has included consolidation, efforts to increase efficiency, and increased demand to demonstrate added value for the money spent. But it is disconcerting that in this drive to increase efficiency and, at least theoretically, to simplify health care, we have created a system that is even more complex and bureaucratic from both a patient and provider perspective. There are more layers between providers and patients, and more barriers to the provision of direct care. Health care has become more impersonal and continuity in health care delivery has actually decreased.

Angaran: Kathy, following up on the remarks by Bert and Mary Anne, we recognize that pharmacy is only one part of the medication use system. There are other health professionals, nurses and physicians and a lot of other people, involved. How well would you say the medication use system is performing today? How are the other health professions, government, and consumers responding to the need to improve the medication use system?

Lake: In general, the medication use system in the U.S. is not performing very well. Although a number of publications point out the problems with our medication use system, I'll comment on only two of them. Tim Lesar and colleagues have published a series of papers that examine medication and prescribing errors in the hospital setting. . $^{2-4}$ Over a 9-year period, the number of such errors increased dramatically. Second, the work done by Bootman et al in the long-term care setting suggests that $\$ 1.33$ is spent on managing the consequences of medication-related morbidity and mortality for every $\$ 1$ spent on the medications themselves. ${ }^{5}$ Something is definitely wrong when we are spending more money on the problems associated with the use of medication than on the medication itself.

Unfortunately, I'm not sure that consumers and the government in general are truly aware of the magnitude of this problem. (Editor's Note: Dr. Lake's comments preceded publication of the report, "To Err is Human" by the Institute of Medicine, which summarized evidence documenting the extent of medical and medication-related errors in the U.S. ${ }^{6}$ ) As a profession, we need to take a leadership role to document the magnitude and costs of these problems. In many respects, our entire system of medication use needs to be reengineered. But it's not our problem alone. Medicine, nursing, and all health professions concerned with medication use must agree that a problem exists and collaborate to conceive and implement a viable solution. Multidisciplinary collaboration will be key-both to finding a solution and as part of the solution itself.

Angaran: Joaquim, Kathy summarized some of the issues that characterize the medication use system in the U.S. How do Europeans perceive these issues, and do you also see the need to improve the medication use system in Europe?

Bonal: Yes, we have similar problems in our medication use system. For example, we recently found that $19 \%$ of patients admitted to our hospital by way of the emergency room were hospitalized because they had a medication-related problem. Further, $29 \%$ of 
patients taking some sort of medication prior to presentation to the emergency room had problems related to those medications. These data suggest that problems associated with medication use in the community setting are of a tremendous magnitude. Cooperation and collaboration between hospital and community pharmacists, and between pharmacists and primary care physicians, will be necessary to solve this problem. But to provide the pharmaceutical care required in the community, our pharmacists must be allowed to exert a higher level of authority in the decision-making process for medication use. This will require support from governmental authorities to enable pharmacists to expand their scope of professional practice.

Angaran: Grethe, health care consumers' and patients' roles in, and attitudes toward, the health system are changing. In America, consumers are much less trusting. They ask more questions. They look for information on their own. And they expect to be more responsible for their own care. Do you perceive a similar change in Europe?

Eide: We have national heath care systems in most European countries. Consequently, people have traditionally taken less responsibility for their own heath care. But now, we are also experiencing a gap between the demand for health care and access. Hence, a commercial private market for health care is emerging in Europe. There is also a growing demand for alternative medical care, suggesting that there is less trust in traditional medicine. People are more aware. They are more questioning. Unfortunately, their information often comes from advertisements or articles in lay magazines that may not be as complete or unbiased as we would like.

We are also experiencing a growth in the elderly population, although this growth rate varies among countries. Also as important, we have a growing group of middle-aged people with lifestyle diseases. Many of these consumers have realized the strength that lies in numbers and have established advocacy organizations according to their disease (diabetes, asthma, organ transplantation, etc.). These groups, who often have strong ties to the pharmaceutical industry, are very effective in representing their interests to heal th authorities and politicians.

This consumer advocacy is accompanied by a push from the government to encourage people to take more personal responsibility for their health, especially when it comes to lifestyle modification.

Angaran: Kathy, Grethe eluded to the emerging role of the consumer in health care. What effects are these changes in consumer attitudes having on the medication use system in the U.S.?

Lake: The changing consumer is affecting medication use in at least two ways. First, as a general rule, consumers are much better informed than they used to be. Second, as $M$ ary Anne mentioned earlier, there is a growing frustration among consumers with the traditional health care system.

A growing number of patients can access a lot of information by way of the Internet that they used to be able to get only from a medical library. It is not unusual for a patient to present to his or her physician or pharmacist carrying some information downloaded from the Internet. As Grethe eluded to, this information is uncontrolled and sometimes of questionable accuracy and integrity. The modern health care consumer can be very astute. They may even "shop around." We have had patients ask about our exact patient and organ transplant survival rates. They want to know exactly what medication protocols are available at our institution. One negative repercussion of this enhanced consumerism is that we have actually experienced difficulty maintaining blinding in clinical research studies because patients have used chat rooms to talk about the studies and can figure out which individuals are on which treatments.

of course, purchasing prescription medications from Internet pharmacies is al ready here. My children's generation will think nothing of shopping over the Internet-for clothes, toys, and prescription medications. This will present a challenge to our traditional view of how clinical pharmacy is practiced and how pharmaceutical care is delivered.

However, just as there are patients who easily access the Internet for health information, there is a large segment of the U.S. population that does not have access. Many of these people are among the elderly population and truly need help with their medication use. Because Medicare does not provide for outpatient medications, some are even forced to make the choice between paying for their medications or 
buying food-food usually wins! Further, patients are getting very frustrated with the health care bureaucracy. They have lost access to their family physician and often must make an appointment weeks or even months in advance- even for relatively acute illnesses. This frustration, in part, is turning many people to alternative forms of medicine. We are now learning that some nutritional supplements or herbal remedies may actually be contributing to patients' drug therapy problems. Unfortunately, many patients won't spontaneously admit that they have been taking an herbal product, and health care providers do not always specifically ask about such use.

Angaran: Bert, you've done some really nice work on scenario analysis in which you described the impact of new technologies, robotics, and information technology on pharmacy. Can you expand your perspective beyond pharmacy and talk about how these emerging technologies will affect the whole medication use system?

Leufkens: Certainly, technology is an important driving force for future change in health care delivery. But is technology the most critical driving force? My answer is no. We were surprised by the results of a scenario analysis we did some years ago to anticipate the treatment of diabetes. We found that the organization of care, individual values, the interrelationship between health care professionals, and the economics of care were more important than technology per se.

of course, information technology is out there, our children play with it, and it will have a big impact. But beyond information technology, genomics will have a major impact on health care in the future. This will include the development of new drugs based on genomics, the ability to individualize therapy better to specific patients, and of course, gene therapy itself.

Unfortunately, we are nowhere near answering the ethical questions raised by genomics. For example, should we screen for certain genetically determined diseases? And if so, what responsibility does the insurance company have to the patient? So yes, technology is a driving force. But the environment in which technology is applied is even more important.
Angaran: Mary Anne, it is estimated that pharmacists filled 2.7 billion prescriptions in this country in 1998. It's been projected that this number will increase to 4 billion by 2002 or 2003. From your perspective as one who is preparing students to enter practice, what is the impact on the practicing pharmacist of the interaction between these projections and the technological changes that Bert and Kathy mentioned?

Koda-Kimble: These trends have not been lost on the chain drug store industry nor on stock market analysts. The consequence of this today is that there is a shortage of dispensing pharmacists in the U.S. Interestingly, 3 years ago we demolished our compounding and dispensing lab. It was an emotional event for some people, but we believed that dispensing is not the best role for pharmacists in the future. I believe that even more strongly today. I also believe that in the next few years there will be a major redesign in the way drugs get to patients. Many of us who practice clinical pharmacy do not dispense drugs. Some have tried to integrate those functions, but I foresee a greater uncoupling and separation of the provision of what some people would now call pharmaceutical care and the dispensing or drug delivery process.

It has been suggested that the pharmacist of the future will be much like an air traffic controller, sitting in some remote tower with a computer in front of him or her, having access to a lot of information, and directing "drug traffic" - that is, drug interventions and the like. That vision seems to be more and more the case. We must get more efficient. The one pharmacist-one patient model from the past may not be the norm in the future.

Angaran: Joaquim, you have held important positions within both the Spanish government and World Health Organization related to drug policy and management. Certainly, society guides health care through its governmentdeveloped regulations, through ethics, and by setting priorities. Can you describe the societal and political dynamics in Europe that will affect the future medication use system?

Bonal: There are very substantial differences between the U.S. health system and the European health systems. In Europe, as has been pointed out, most countries have a statefinanced health system that provides access for 
everybody. In general, the population is satisfied with this public system, in part because they could not afford to pay for their health care directly. But all systems have advantages and disadvantages. One disadvantage of the European public system is that the money to fund it comes from the general taxes, which cannot be increased without limits. This causes an obvious problem when demand is growing and the resources are limited. Naturally, this has led the governments to establish various cost-control measures. With regard to pharmaceuticals, this has included establishing a higher copayment by the patient, price controls imposed on manufacturers, and reducing public financing for some drugs with negative risk profiles. In general, these measures have had very limited results. Occasional conflicts occur between the population-based health system like that found in most countries in Europe and individual patient care. In other words, what may be best for society as a whole may not be best for a specific individual.

Angaran: Grethe, you've been involved in developing new hospital and community-based practices in Norway. From your perspective, where is Europe now in the development of the pharmaceutical care concept in community practice?

Eide: As you know, the largest part of medication use occurs in the community health care setting. In general, Europeans are just beginning to implement the pharmaceutical care philosophy. As expected, there are great variations within countries and from one country to another. However, success has come as a result of a greater focus on the consumer's needs and the requirement to establish quality assurance systems in community pharmacies.

But providing pharmaceutical care requires knowledge and skills that few pharmacy schools in Europe provide to their students. Newly graduated pharmacists may know a lot about drugs, but they know very little about patients. Hence, the role models these students encounter when they enter practice, and onthe-job training available to them, are very important. A drive is underway to change pharmacy practice in many European countries, and there are several national demonstration projects that have begun.
Angaran: Mary Anne, many U.S. pharmacists have adopted the pharmaceutical care philosophy. Ten years ago you made some interesting observations about the diffusion of this philosophy into community practice. Where are we now in making this concept a reality, and where do you think we will be 5 years from now?

Koda-Kimble: It's important to realize that pharmaceutical care is not the sole property of pharmacy. Pharmaceutical care is provided by nurses, physicians, and many other practitioners. We want to take ownership of it because it has "pharma" in front of it. In my view, clinically trained pharmacists are alive and well. Despite all of the changes, challenges, and turmoil we have discussed thus far, this very change and turmoil has created many new opportunities. Clinical pharmacists in institutional practice have documented very well the value of their services. Now, these practitioners are moving into community or ambulatory care. Certainly, managed care has opened up many new opportunities for clinical pharmacists. We are applying the same principles and concepts in the managed care environment that we learned in the institutional setting. Some of my residents have joined Internet-based pharmacies where they are dispensing individualized information, not drugs. Clinical pharmacists are partnering with physician groups. The pharmaceutical industry has recognized the value of the clinical pharmacist and represents an expanding career opportunity. I feel very optimistic about all of this. I must admit, though, that I'm not so optimistic about the future of pharmacy practice if it is based principally on the dispensing of drugs.

Angaran: During the first part of this session, we have tried to describe two cultures that, even though separated by an ocean, sound remarkably similar. We would now like to focus on pharmacy, and the challenges and opportunities that lie ahead. Joaquim, the practice philosophy of pharmaceutical care embodies one central notion-a shared responsibility by pharmacists for patient outcomes. Where is European pharmacy in assuming this shared responsibility?

Bonal: Adoption of pharmaceutical care as a philosophy of practice is growing. For example, in Spain a group of community 
pharmacists recently created the Pharmaceutical Care Foundation. Also in Spain, ambulatory patients in some communities receive care from hospital-based specialist physicians. This has provided a new opportunity for hospital pharmacists to participate in primary care and to cooperate with pharmacists working in the community setting. This allows direct communication and cooperation among different professionals to improve drug use in the community.

The questions are, how can we, as pharmacists, be allowed to take more responsibly for the prescribing and use of drugs? How can community pharmacists be paid for their professional services? I think the answers to these questions will come only when we have enough documentation that the pharmacists' services are improving the health of the population and benefiting the overall health system.

Angaran: Kathy, how can we improve our current situation in the U.S. with regard to pharmacists broadly assuming shared responsibility for the pharmaceutical care of their patients?

Lake: We really need a profession-wide transformation. So many pharmacists cling to the old ways of practicing and doing business. We heard comments earlier about our dysfunctional medication use system. The evidence is al ready strong that pharmacists can help solve these problems. We have an opportunity right now if we pull together. Every pharmacist should consider it his or her duty to tell patients and other health professionals about the value of clinical pharmacy services. In addition, we all should make a commitment to get involved politically and to communicate the benefits of clinical pharmacy services at every opportunity.

Angaran: Mary Anne, as a pharmacy educator, what further changes are necessary in pharmacy education to prepare our graduates to assume this shared responsibility for providing pharmaceutical care?

Koda-Kimble: Over the last few years, the obvious big event that's happened in the U.S. is the adoption of the Doctor of Pharmacy as our single entry-level degree. That has, of course, caused tremendous change across the country as schools augment and revise curricula to increase the clinical component. And that is good. But here is where I worry. I think we need to go back to the basics. Some of us can remember that pharmacist of years past who took the initiative, who took risks, who was entrepreneurial, who cared, who made decisions out there in the field. I believe our profession has lost many of those values and qualities, but we need them back in the pharmacists that we're training for the future.

Second, science is the basis of a profession. I fear that we are discarding some of the basic sciences in our curriculum in favor of the clinical sciences. Speaking for myself as a clinician, I am sometimes at a loss, conceptually, when I read about many of today's new drugs because the pace of discovery in the basic sciences has been so astounding. For the pharmacists that we are training now, as well as the professionals already in practice, basic science must be part of our entry-level and continuing professional education. Further, we also have to be knowledgeable about health care systems, politics, and economics. Because of the importance of documenting the value of pharmacy services to patients and the health system, now and in the future, every student should also have some rudimentary skills in pharmacy practice research.

Angaran: Grethe, you've been interested in clinical pharmacy education in Europe for quite some time. Could you comment and expand on Mary Anne's remarks from a European perspective?

Eide: In Europe, clinical pharmacy has generally not yet been accepted as part of pharmacy education. Most undergraduate programs are based on the natural sciences. Although there have been some major changes through the years, with greater emphasis on pharmacotherapeutics and problem-based learning, clinical pharmacy is still more a part of graduate programs-like master's degree programs or hospital pharmacy specialization programs. In addition, the number of students able to enter such clinical programs is limited because there are few programs available.

Angaran: Bert, we have described a number of changes in society, health care, and therapeutics. From your perspective, what would you suggest the research agenda should be to support our evolving profession?

Leufkens: First of all, I agree with Mary Anne 
that science is an integral part of our profession. In the $\mathrm{Netherlands,} \mathrm{we} \mathrm{are}$ fortunate that all pharmacy students have a 6month research experience as part of their undergraduate training. This experience is important not only in developing their scientific skills but also in shaping their attitudes toward science as they enter practice. It also provides a link between academia and practice.

But to directly answer your question, there are two areas of research that I believe need much greater emphasis: pharmacy practice research and pharmacoepidemiology. As in the U.S., the need for pharmacists to do practice research to document the value of their expanding services is very real. Pharmacoepidemiology is important because of the issue of drug-related problems. We know so little about a drug's effects after it is released on the market, yet the problems are very real.

Angaran: Grethe, the same basic question to you: from your perspective as a community practitioner in Europe, what should the pharmacy research agenda be to support your needs?

Eide: My ideas parallel those of Bert. I see three very important areas. The first is postmarketing studies regarding drug safety and efficacy. Despite all the money put into clinical trials, they test a drug in very limited groups and often don't really predict what happens when the drugs are used more widely. Second is outcome and pharmacoeconomic studies. And third is more research on pharmacy practice to assess how pharmacy intervention can be costeffective to society.

Angaran: Joaquim, how health care and pharmacy services are financed in many European countries is much different than in the U.S. From your perspective, what political and regulatory changes will enable clinical pharmacy diffusion within Europe?

Bonal: Pharmacists need governmental authority to assume more responsibility in the drug therapy decision-making process. But because laws always follow social change, efforts should be made to obtain more evidence that clinical pharmacy services enhance patient outcomes and improve the health care system. Unfortunately, we have very little documentation to that effect in Europe.

Also, there are large differences between the schools of pharmacy in the U.S. and those in Europe. Although some schools of pharmacy in Europe are supportive of clinical practice, others actually oppose the concept. This creates a gap, which must be resolved, between the schools of pharmacy and the practitioners. More practitioners must be involved in the university.

Angaran: Mary Anne, these dynamic changes in society and health care are going to result in some very interesting ethical issues that our profession and practitioners have not had to face before. Can you comment?

Koda-Kimble: I think it is going to be a huge challenge to maintain a focus on our core values as a profession, not because of the shift in emphasis but because of who's controlling health care. Who delivers care, who gets care, and what kind of care will be delivered? It is being driven more by businessmen and less by the independent practitioner. The other challenge for us as pharmacists will be to take a stand on some of the larger issues. For example, should drugs be covered by health insurance and Medicare? Our positions will likely find us on the opposite side of the issue from the pharmaceutical industry. At the same time, we are trying to collaborate, cooperate, and develop partnerships with industry. This will be a real challenge.

Angaran: To conclude, I would like to ask each of our panelists for their recommendations. What can individual pharmacists do, what can pharmacy education do, and what can pharmacy organizations do to help position our profession to best meet the pharmaceutical care needs of society?

Leufkens: First, pharmacists must be innovative and assume leadership roles in their environments. The gap between community and hospital practice must be eliminated. Many diseases once treated predominantly in the hospital are now managed in the community. Continuity of care is crucial.

Second, as educators we must do a better job to provide our students with enhanced communication and cognitive skills, as well as an appreciation for science. Finally, I am a strong believer in individual leadership. Pharmacy associations must do a better job identifying the key leaders among their membership, put them in place, and let them do their job. Too many professional organi- 
zations become very bureaucratic and do not allow the members to guide the association.

Koda-Kimble: Pharmacists must be at the table to influence change. It is easy to be overwhelmed by all the changes taking place. But we have to remember that it is one pharmacist at a time, one patient at a time, one action at a time. To the extent that every single pharmacist can take responsibility for what he or she can control, we will begin to move forward.

With regard to pharmacy education, our responsibility is to inspire. We are creating a future. We need to create a sense of idealism and a vision. Students must enter practice dissatisfied with the status quo and sustain that attitude throughout their careers. As it relates to professional organizations, I would ask them to emulate the marketplace. They need to consolidate, or at the very least to collaborate. They need to find a single message that will communicate the value of pharmacists to the public. "Pharmaceutical care" is not that message. It is too complicated. We need to break it down into something simple, and we need to all be repeating the same message every time. The pharmaceutical industry has done this: they create new drugs to cure disease. What do pharmacists do?

Eide: It is important that consumers be convinced that they can trust their pharmacist, and individual pharmacists must be cautious not to violate that trust. As far as pharmacy education is concerned, schools in Europe should analyze society's needs for improved drug therapy outcomes and produce pharmacists capable of addressing those needs. Professional organizations must convince health authorities of the beneficial impact pharmacists can have on drug use and on health care budgets.

Bonal: Many pharmacists must change their attitudes about professional practice and improve their clinical knowledge and skills. In Europe, the schools of pharmacy have to change their curricula completely. The current curriculum is no longer acceptable. They must start by defining the objectives of pharmacy education. Many schools educate pharmacists to work in the pharmaceutical industry and governmental agencies dealing with food control and other things that have nothing to do with the use of drugs. And finally, pharmacy organizations have to exert more political pressure. They must work to expand the authority of pharmacists and must pressure the schools of pharmacy to change their programs. They also have to promote and finance research projects to document pharmacists' contributions to better health.

Lake: All pharmacists must make a commitment to improve the therapy of their patients. Beyond that, I would like to see each pharmacist commit to educating someone else about the value of our services- not just an administrator in his or her institution, but patients, legislators, insurance companies, etc. This will take many people outside their comfort zones, but it can have a major impact.

Concerning pharmacy education, schools should develop their curricula with the desired outcomes in mind. What knowledge and skills does a pharmacist need to optimize drug therapy outcomes? Every aspect of the curriculum must work toward that end. And finally, this is a crucial time for our professional associations to work together. There may be certain organizations whose constituents prefer the status quo. But there is some urgency in redefining pharmacy's societal role. We have a challenge, yes. But we also have a tremendous opportunity, and I am confident that we will succeed.

\section{References}

1. Francke DE. Sydney E. Wright Memorial Lecture, University of Sydney, Sydney, Australia, October 8, 1976.

2. Lesar TS, Lomaestro BM, Pohl H. Medication prescribing errors in a teaching hospital. A 9-year experience. Arch Intern Med 1997;157:1569-76.

3. Lesar TS, Briceland L, Stein DS. Factors related to errors in medication prescribing. JAMA 1997;277:312-7.

4. Lesar TS, Briceland LL, Delcoure K, Parmalee JC, MastaBomic V, Pohl H. Medication prescribing errors in a teaching hospital. JAMA 1990;263:2329-34.

5. Bootman JL, Harrison, DL, C ox E. The health care cost of drug-related morbidity and mortality in nursing facilities. Arch Intern Med 1997;157:2089-96.

6. Kohn LT, Corrigan JM, Donaldson MS, ed. To err is human: building a safer health system. Washington, DC; National Academy Press; 1999. 